\title{
Addressing decreasing blood lead screening rates in young children in Broken Hill, NSW
}

\section{Katina Kardamanidis ${ }^{\mathrm{A}, \mathrm{D}}$, David M. Lyle L $^{\mathrm{B}}$ and Frances Boreland ${ }^{\mathrm{C}}$}

ANSW Public Health Officer Training Program, NSW Department of Health

B Broken Hill University Department of Rural Health, University of Sydney

${ }^{\mathrm{C}}$ Broken Hill Centre for Remote Health Research, Joint Initiative of the University of Sydney and Greater Western Area Health Service

${ }^{\mathrm{D} C o r r e s p o n d i n g ~ a u t h o r . ~ E m a i l: ~ K a t i n a . K a r d a m a n i d i s @, ~}$ doh.health.nsw.gov.au

\begin{abstract}
This paper outlines the findings of a review commissioned in response to concerns about declining attendance of young children for blood lead screening in Broken Hill, NSW. A review of the literature and feedback from the local community revealed that reasons for reduced screening attendance elsewhere can be applied here, but that any proposed response should take account of local conditions.

Redressing the declining attendance for blood lead screening will require more than raising community awareness, educating carers and enhancing the acceptability of the screening service. A whole-of-community approach to environmental lead management that goes beyond the specific responsibilities of the health sector is required.
\end{abstract}

Broken Hill is a mining town of over 19000 people located in far west New South Wales (NSW). The town is built around one of the world's largest silver-lead-zinc ore bodies. ${ }^{1}$ Since 1991, children under the age of 5 years have been offered annual screening to assess the level of lead in their blood as part of an environmental lead management program. $^{2-4}$ Blood lead screening is the only reliable way to identify children with high blood lead levels so that preventive measures can be taken to reduce the detrimental health effects of lead. 5,6

The Broken Hill Lead Management Program initially operated out of a dedicated centre, but in 2001 the Program was integrated into mainstream health and other communitybased services. The local child and family health centre is now responsible for delivering the Lead Health Program, which involves blood lead monitoring; case finding and management; and community education.

The local area health service was concerned about declining levels of attendance at blood lead screening. The decreased attendance rate was occurring in the context of a program that had been successful in reducing mean blood lead levels, but where around one-quarter of the 451 children tested in 2007 still had elevated blood lead levels $(\geqslant 10 \mu \mathrm{g} / \mathrm{dL}){ }^{7}$

We report on a review commissioned to determine why blood lead screening attendance in Broken Hill has declined and propose actions to increase screening rates.

\section{Review methods}

We analysed routinely collected data from the Lead Health Program and reviewed the literature to document factors associated with screening attendance. ${ }^{8,9}$ We used focus groups to consult with 48 community members who responded to invitations through notices placed in public areas and newspapers. We also sought feedback, using semi-structured interviews, from a range of health professionals and organisations about ways in which their services might contribute to blood lead screening attendance rates. Health promotion models and theories were used to inform the interviews, which explored individual, organisational, social and political factors that may contribute to screening attendance. ${ }^{10,11}$

\section{Key findings}

Analysis of routinely collected data showed that attendance rates for screening of pre-school children in Broken Hill have declined significantly from $73 \%$ of eligible children in 1998 to $48 \%$ in 2007 and that parents are now waiting longer before bringing children in for their first screening test. ${ }^{8}$ Screening rates were higher in the youngest children; those living closer to the mines; boys; and the Aboriginal community. ${ }^{8}$

We identified a number of potential factors in the published literature that explain reduced screening attendance, including: the perception of not being at risk and previous low blood lead levels; concerns about the screening 
procedure, especially if the test is invasive or causes discomfort; a previous (self or friend) negative experience; fear of the outcome; and beliefs that nothing can be done to treat the problem. Practical issues can also have a negative impact on attendance, such as: difficulty accessing the service; forgetting that the test is due; and being too busy to attend. ${ }^{9}$ Factors associated with higher screening attendance rates include the use of targeted outreach activities, such as screening children in their homes; intensive screening during short periods; and personalised invitations to screening with definite appointment times. People who have attended screening before are more likely to return for the next test and encouragement by general practitioners and health service providers can positively influence screening rates. ${ }^{9}$

Community consultations and interviews with health professionals revealed that many of the reasons for attending or not attending screening reported in the literature can be applied to Broken Hill. Some important issues, however, appeared to be unique to the local conditions, namely the observed decrease in activities to promote lead awareness and cessation of financial support for families to remove lead dust from their homes. Reactions to these observations ranged from an interpretation that environmental lead is apparently no longer a problem in Broken Hill, to an expectation that, as in the past, the government and the mining industry should take responsibility for preventive measures that are beyond the capacity of an individual family.

\section{Discussion}

Reversing the trend of decreasing lead screening rates in pre-school children requires raising community awareness, educating parents and improving accessibility to the screening program. Each of these approaches needs to be incorporated into an effective response strategy. The strategy should also take account of local conditions. A broader approach to increasing blood lead screening rates must be taken, and environmental lead management in Broken Hill must go beyond the specific responsibilities of the health sector. This approach needs to take into account prevailing community views that lead management is no longer a priority issue and that the previous commitment by public agencies to invest in solving the problem has diminished.

Successful lead management programs from Australia and overseas have incorporated contributions from the health sector, local and state government, industry and community groups. ${ }^{12-16}$ Such an approach would enable effective interventions to be applied at the individual, neighbourhood and community level, including industry practices in relation to mining and transport of lead ore.

It is important that the Broken Hill community is kept informed about changes to the Lead Health Program and that community members are engaged as participants in the strategy, as it evolves. This inclusive approach would help reverse perceptions that environmental lead is no longer a problem or that nothing more can be done by individual families to address it - two local factors reported as barriers to screening.

\section{Acknowledgments}

The authors would like to acknowledge the important contribution to this project from Vilmae McManus, Kelli Schultz and Angela Tiziani of the Lead Health Program.

\section{References}

1. Australian Bureau of Statistics. Census QuickStats: Broken Hill (Urban Centre/Locality). 2006. Available from: http://www.censusdata.abs.gov.au/ (Cited 28 May 2008.)

2. Lyle DM, Phillips A, Balding W, Burke H, Stokes D, Corbett S et al. Dealing with lead in Broken Hill: trends in blood lead levels in young children 1991-2003. Sci Total Environ 2006; 359: 111-9. doi:10.1016/j.scitotenv.2005.04.022

3. Lyle D, Balding B, Burke H, Begg S. NSW Lead management program in Broken Hill. NS W Public Health Bull 2001; 12(6): 165-7. doi:10.1071/NB01054

4. Burke H, Balding B, Lyle D. Reducing lead exposure in children in Broken Hill. N S W Public Health Bull 2003; 14(3): 52-4. doi:10.1071/NB03016

5. Centers for Disease Control and Prevention. Preventing lead poisoning in young children: a statement by the centers for disease control and prevention. Atlanta: Centers for Disease Control and Prevention; 1991. Available from: http://www.cdc.gov/nceh/lead/publications/books/plpyc/ contents.htm (Cited 28 May 2008.)

6. Centers for Disease Control and Prevention. Recommendations and Reports: interpreting and managing blood lead levels $<10 \mu \mathrm{g} / \mathrm{dL}$ in children and reducing childhood exposures to lead. MMWR 2007; 56(RR08): 1-16.

7. Centers for Disease Control and Prevention. Managing elevated blood lead levels among young children: Recommendations from the Advisory Committee on Childhood Lead Poisoning Prevention. Atlanta: CDC; 2002. Available from: http://www.cdc.gov/nceh/lead/ CaseManagement/caseManage_main.htm (Cited 28 May 2008.)

8. Boreland F, Lyle D. Using performance indicators to monitor attendance at the Broken Hill Blood Lead Screening Clinic. Environ Res 2008; In press.

9. Boreland F, Lyle D. Screening children for elevated blood lead: learnings from the literature. Sci Total Environ 2008; 390: 13-22. doi:10.1016/j.scitotenv.2007.09.041

10. Green LW, Kreuter MW. Health Promotion Planning: An Educational and Ecological Approach. 3rd ed. Mountain View, CA: Mayfield; 1999.

11. Nutbeam D, Harris E. Theory in a nutshell: a practical guide to health promotion theories. 2nd ed. Sydney: McGraw-Hill; 2004.

12. Elias RW, Gulson B. Overview of lead remediation effectiveness. Sci Total Environ 2003; 303: 1-13. doi:10.1016/S00489697(02)00361-3 
13. Sheldrake S, Stifelman M. A case study of lead contamination cleanup effectiveness at Bunker Hill. Sci Total Environ 2003; 303: 105-23. doi:10.1016/S0048-9697(02)00354-6

14. Hilts SR. Effect of smelter emission reductions on children's blood lead levels. Sci Total Environ 2003; 303: 51-8. doi:10.1016/S0048-9697(02)00357-1

15. Maynard E, Thomas R, Simon D, Phipps C, Ward C, Calder I. An evaluation of recent blood lead levels in Port Pirie, South
Australia. Sci Total Environ 2003; 303: 25-33. doi:10.1016/S0048-9697(02)00359-5

16. The Port Pirie Lead Implementation Program. Future focus and directions. Adelaide: Department of Health; 2005. Available from: http://www.health.sa.gov.au/PEHS/PDF-files/ptpiriefuture-focus $=05$. pdf (Cited 28 May 2008.) 